UDC 613.648.2+654.164: 616.1

DOI: 10.21668/health.risk/2021.3.07.eng

Research article

\title{
ELECTROMAGNETIC ENVIRONMENT CREATED BY MOBILE COMMUNICATION AS A RISK FACTOR CAUSING HIGHER PREVALENCE OF CIRCULATORY DISEASES
}

\author{
S.E. Shibanov, S.G. Yashchenko, S.Yu. Rybalko \\ V.I. Vernadsky Crimean Federal University, 5/7 Lenina Boulevard, Simferopol, 295007, Russian Federation
}

Our research goal was to examine energy and time parameters of electromagnetic environment created by mobile communication terminals in Crimea and to detect a relationship between morbidity with diseases of the circulatory system (DCS) among people living in the republic due to electromagnetic environment.

Electromagnetic environment was determined as per energy flux density (EFD) at terminals, average daily electromagnetic exposure (ADEE) and individual electromagnetic burden (IEB). Correlation analysis of all the obtained data was performed to detect possible correlations with diseases of the circulatory system.

Measurements of electromagnetic environment created by terminals in the region during a period from March 2019 to February 2020 (4,204 measurements at points where people used mobile communications intensely) yielded the following results: average EFD value amounted to $1.43 \pm 0.04 \mu \mathrm{Wt} / \mathrm{cm}^{2}$; IEB, $117.80 \pm 6.55\left(\mu \mathrm{Wt} / \mathrm{cm}^{2}\right) \cdot \mathrm{min}$; ADEE, $60.56 \pm 1.15 \mathrm{~min}$.

Electromagnetic environment parameters and prevalence of the most common DCS in Crimea were statistically processed and the following authentic correlations were revealed: between overall morbidity with circulatory diseases and energy $(E F D(T a u=0.399 ; p<0.01))$ and integral (IEB (Tau=0.437; $p<0.01))$ properties of electromagnetic radiation; between overall morbidity with diseases that involved elevated blood pressure and IEB (Tau=0.377, $p=0.01)$; between primary morbidity with diseases that involved elevated blood pressure and all electromagnetic radiation properties: EFD $($ Tau $=0.304, p=0.04)$, IEB (Tau=0.342, $p=0.02)$, and ADEE (Tau=0.299, $p=0.04)$; between primary morbidity with cerebrovascular diseases $(C V D)$ and $A D E E(T a u=0.411, p<0.01)$ as time property of the examined factor.

Energy and time parameters of electromagnetic environment created by mobile communication terminals that have been measured in Crimea are authentically correlated with distribution of morbidity with circulatory diseases and exert their influence on a risk of probable growth in morbidity with these nosologies among people living in Crimea.

Key words: electromagnetic radiation, electromagnetic burden, mobile phone, primary diseases, pathology of the circulatory system.

Diseases of the circulatory system have significant influence on labor and life potential of the contemporary world society as well as demographic safety of any state; they are a vital issue for contemporary medicine since such diseases are among primary causes of population mortality $[1,2]$. However, morbidity with diseases of the circulatory system and its outcomes for population are different in different countries. Thus, an authors' team conducted a research work based on analyz- ing trends in morbidity over 2001-2016 in Great Britain and as a result it was established that life expectancy grew approximately by 3 years per a decade. The primary factor here was a decrease in frequency of hospitalizations, first of all, due to diseases of the circulatory system [2].

Statistical data collected in Belarus were analyzed; as a result, the authors detected a decrease in primary morbidity with diseases from this nosologic category by $16 \%$ from

(c) Shibanov S.E., Yashchenko S.G., Rybalko S.Yu., 2021

Sergey E. Shibanov - Doctor of Medical Sciences, Head of the Department for Common Hygiene with Ecology (e-mail: seshibanov@mail.ru; tel.: +7 (3652) 554949; ORCID: http://orcid.org/0000-0002-9322-5836).

Svetlana G. Yashchenko - Candidate of Medical Sciences, Associate professor the Department for Common Hygiene with Ecology (e-mail: yswet.net@mail.ru; tel.: +7 (3652) 554949; ORCID: http://orcid.org/0000-0001-6817-8639).

Sergei Yu. Rybalko - Candidate of Biological Sciences, Associate professor at the Department for Condensed Matter Physics, Physical Methods and Information Technologies in Medicine (e-mail: kphis012@andex.ua; tel.: +7 (3652) 554949). 
2011 to 2015 [3]. In Russia in 2018 a number of registered cardiovascular diseases grew by $12.68 \%$ against $2010^{1}$. When analyzing specific nosologies within the category, for example, hypertensive diseases, experts detected that morbidity grew by $28.12 \%$ including first diagnosed cases that grew by $78.69 \%{ }^{1}$. Foreign researchers pay close attention to conventional factors that influence risks of cardiovascular diseases (imbalanced nutrition, low physical activity, overweight, etc.) and their scientifically grounded correction [4]. Some research works focus on patients' age and there are conclusions in them on the necessity to implement efficient preventive activities for middle-aged and elderly people [1]. Domestic researchers have revealed impacts exerted by climatic-geographic and ecologic factors on deviations in population health in a given region from the country trends [5].

At the same time there are data on effects produced on non-carcinogenic health risks by electromagnetic radiation (EMR) created in radio frequency (RF) spectrum [6, 7]. New procedures are being developed to estimate intensify of electromagnetic background and population exposure [8] and there are studies focusing on possible health risks caused by environmental pollution with electromagnetic fields generated by mobile phone base stations [7]. Levels of electromagnetic fields (EMF) are being examined, among other things, within a context of assessing population exposure [9].

It is quite promising to examine epidemiologic situation regarding cardiovascular diseases in regions with different climatic and geographic conditions [5]. In this respect Crimea seems an interesting region, especially given mass reconstruction of mobile communications that is taking place in the republic at the moment. It allowed us to formulate our research goal that was to examine energy and time parameters of electromagnetic environ- ment created by mobile communication terminals in Crimea and to detect a relationship between electromagnetic environment and morbidity with diseases of the circulatory system among population in the republic.

Data and methods. We took data from statistical reports issued over 2015-2019 to analyze primary and total morbidity with diseases of the circulatory system among population in Crimea; the data were provided by the Crimean Medical and Information Analytical Center. We analyzed total and first detected morbidity rates calculated as per 100 thousand people living in Crimea; rates were analyzed for the following classes of diseases according to the International classification of diseases (ICD-10) (the latest edition as of 2019): hypertensive diseases, ishaemic heart diseases, and cerebrovascular diseases.

We applied several parameters to estimate electromagnetic environment: energy flux density (EFD) as an energy parameter of EMR produced by mobile communication terminals; average daily electromagnetic exposure (ADEE) as a time parameter of the examined factor; and individual electromagnetic burden (IEB) as an integral parameter that depended both on energy flux density and duration of exposure.

Electromagnetic environment was estimated in 22 administrative districts in Crimea through mobile monitoring over energy flux density in radio frequency spectrum of radiation created by mobile communication terminals. To do that, we used PZ-34 measuring device (NTM "Zashchita", Moscow, RF) with AP 3-34 VNF antenna. The antenna was fixed on a support device together with two Samsung A30 mobile phones 0.37 meters away from them and was located in a box on a car's trunk. MS2712E portative spectrum analyzer (Anritsu, USA) with Aaronia AG antenna (Aaronia, Germany) was used at each measuring point to analyze the background and to remove side EMF sources in radio frequency

${ }^{1}$ Zdravookhranenie v Rossii. 2019: stat. sb. [Public healthcare in Russia. 2019: statistical data collection]. Moscow, Federal State Statistic Service Publ., 2019, pp. 70-78 (in Russian). 
spectrum. Then, we determined energy flux density three times during 1 minute at 1.7 meters high, both background level and those created by each mobile phone during a phone conversation with a remote interlocutor (provided that background level was lower than $0.5 \mu \mathrm{W} / \mathrm{cm}^{2}$ ). We determined access burst (AB) for each call, a time period necessary to establish a connection during which a mobile phone creates maximum electromagnetic radiation; duration of this period is linearly dependent on overall loads on a mobile network in a given region [8]. To determine an average duration of a phone conversation, we applied crowdsourcing that involved collecting data on time spent on using mobile phones provided by volunteers. They collected data on average daily time spent on using mobile phones from detail reports on phone calls provided by Mobile TeleSystems (MTS). We calculated individual electromagnetic burden (IEB) using data on EFD, duration of a phone conversation and correction index CI (normalizaiton of a current value to a minimum one detected in a given region). To estimate duration of people's exposure to the examined factor, we took average daily electromagnetic exposure (ADEE) [8] that was calculated taking into account duration of a phone call, CI, and average daily number of phone conversations determined according to detail reports on phone calls. Experimental data were tested to determine whether distribution was normal according to Kolmogorov - Smirnov procedure. In case a data series was distributed normally, we calculated simple mean and error of mean; if distribution was not normal, we calculated median $(\mathrm{Me})$ and upper and lower quartiles $(Q 1 ; Q 3)$. Data series with normal distribution were tested with Pearson's linear correlation analysis to detect any correlations; data series with distribution that was not normal, with Kendall rank correlation coefficient.

Results and discussion. Having analyzed data on morbidity with diseases of the circulatory system among population in Crimea over 2015-2019, we were able to calculate medians (Me $(Q 1 ; Q 2))$ of total morbidity that amounted to $47,923.3(43,230.1 ; 51,877.8)$ cases per 100 thousand people for diseases of the circulatory system; 18,266.6 (6,877.7; 19,747.5), for hypertensive diseases; $19,543.9$ $(18,742.1 ; 20,740.2)$, for ishaemic heart diseases; and 6,050.7 (5,557.8; 6,676.2), for cerebrovascular diseases. Therefore, we can note that diseases of the circulatory system are mostly ishaemic heart diseases and hypertensive diseases. As for primary morbidity with diseases of the circulatory system among population, medians calculated for primary morbidity amounted to 2,911.8 (2,780.2; $4,355.7)$ for diseases of the circulatory system; $697.2(688.2 ; 1,187.0)$, for hypertensive diseases; $906.6(808.9$; $1,538.4)$, for ishaemic heart diseases; and 811.7 (774.2; 951.8), for cerebrovascular diseases. Given that, it seems interesting that a share of cerebrovascular diseases has grown considerably in the structure of primary morbidity with diseases of the circulatory system in comparison with the same parameter in total morbidity with the same diseases.

Experimental studies on electromagnetic environment created by mobile communications in the region from March 2019 to February 2020 (4,204 measurements accomplished at points where people used mobile communications quite actively) yielded the results given in Table.

Calculated average EFD values varied from $0.94 \pm 0.03 \mu \mathrm{W} / \mathrm{cm}^{2}$ (Belogorskiy district) to $2.04 \pm 0.06 \mu \mathrm{W} / \mathrm{cm}^{2}$ (Simferopol); average value in Crimea was $1.43 \pm 0.04 \mu \mathrm{W} / \mathrm{cm}^{2}$, and simultaneously measured access burst (AB) varied from $6.35 \pm 0.19 \mathrm{sec}$ (Dzhankoyskiy district) to $11.31 \pm 0.41 \mathrm{sec}$ (Simferopol), average value in Crimea was $9.05 \pm 0.41 \mathrm{sec}$. Average daily duration of phone conversations varied from $44.5 \pm 2.76 \mathrm{~min}$ (Pervomaiskiy district) to $67.51 \pm 3.07 \mathrm{~min}$ (Yalta), and average value in Crimea amounted to $56.94 \pm 2.77 \mathrm{~min}$. Average calculated IEB in the region amounted to $117.80 \pm 6.55$ $\left(\mu \mathrm{W} / \mathrm{cm}^{2}\right) \cdot \min$. Having analyzed the parameter in greater detail, we spotted out cities (Simferopol $\left(254.11 \pm 11.51\left(\mu \mathrm{W} / \mathrm{cm}^{2}\right) \cdot \min \right)$, 
Parameters of electromegnatic environment created by mobile communications on administrative districts in Crimea in 2019-2020

\begin{tabular}{|l|c|c|c|c|c|}
\hline \multicolumn{1}{|c|}{$\begin{array}{c}\text { Adminitrsative } \\
\text { district }\end{array}$} & $\begin{array}{c}\mathrm{EFD}^{1} \\
\left(\mu \mathrm{W} / \mathrm{cm}^{2}\right)\end{array}$ & $\begin{array}{c}\text { Access burst } \\
(\mathrm{sec})\end{array}$ & $\begin{array}{c}\text { Duration of phone } \\
\text { calls a day }(\mathrm{min})\end{array}$ & $\begin{array}{c}\mathrm{IEB}^{2} \\
\left(\mu \mathrm{W} / \mathrm{cm}^{2} \cdot \mathrm{min}\right)\end{array}$ & $\begin{array}{c}\text { Average daily } \\
\text { exposure (min) }\end{array}$ \\
\hline Crimea & $1.43 \pm 0.04$ & $9.05 \pm 0.41$ & $56.94 \pm 2.77$ & $117.80 \pm 6.55$ & $60.56 \pm 1.15$ \\
\hline Simferopol & $2.04 \pm 0.06$ & $11.31 \pm 0.23$ & $67.32 \pm 1.94$ & $254.11 \pm 11.51$ & $72.96 \pm 1.34$ \\
\hline Yevpatoria & $1.30 \pm 0.05$ & $9.39 \pm 0.68$ & $58.11 \pm 2.45$ & $108.09 \pm 5.11$ & $62.79 \pm 1.07$ \\
\hline Feodosyia & $1.22 \pm 0.05$ & $9.39 \pm 0.71$ & $55.62 \pm 1.87$ & $102.75 \pm 4.89$ & $60.30 \pm 1.75$ \\
\hline Kerch & $1.11 \pm 0.04$ & $8.08 \pm 0.43$ & $62.41 \pm 3.44$ & $79.60 \pm 3.94$ & $60.44 \pm 0.89$ \\
\hline Yalta & $1.45 \pm 0.05$ & $9.99 \pm 0.51$ & $67.51 \pm 3.07$ & $156.44 \pm 6.17$ & $72.49 \pm 1.11$ \\
\hline Alushta & $1.52 \pm 0.06$ & $11.13 \pm 0.44$ & $47.10 \pm 2.75$ & $124.76 \pm 4.34$ & $52.67 \pm 2.97$ \\
\hline Armyansk & $1.09 \pm 0.04$ & $7.94 \pm 0.17$ & $45.28 \pm 3.10$ & $64.11 \pm 2.84$ & $49.17 \pm 1.91$ \\
\hline Sudak & $1.34 \pm 0.05$ & $9.14 \pm 0.22$ & $62.84 \pm 3.23$ & $120.16 \pm 5.34$ & $67.37 \pm 2.77$ \\
\hline Krasnoperekopsk & $1.74 \pm 0.06$ & $8.89 \pm 0.40$ & $58.55 \pm 2.18$ & $136.16 \pm 4.71$ & $62.95 \pm 2.51$ \\
\hline Bakhchysaray district & $1.23 \pm 0.05$ & $9.71 \pm 0.34$ & $51.91 \pm 2.19$ & $91.26 \pm 3.58$ & $56.76 \pm 2.75$ \\
\hline Belogorskiy district & $0.94 \pm 0.03$ & $7.57 \pm 0.29$ & $46.46 \pm 1.88$ & $54.13 \pm 1.87$ & $50.19 \pm 1.77$ \\
\hline Dzhankoyskiy district & $1.24 \pm 0.04$ & $6.35 \pm 0.19$ & $64.86 \pm 2.54$ & $80.35 \pm 2.90$ & $67.85 \pm 2.54$ \\
\hline Kirovskiy district & $1.24 \pm 0.05$ & $8.62 \pm 0.28$ & $58.21 \pm 2.32$ & $104.58 \pm 2.15$ & $62.62 \pm 2.82$ \\
\hline Krasnogvardeiskiy district & $1.76 \pm 0.06$ & $9.44 \pm 0.32$ & $65.44 \pm 2.95$ & $152.17 \pm 5.52$ & $70.16 \pm 3.72$ \\
\hline Lenisnkiy district & $1.48 \pm 0.05$ & $9.36 \pm 0.26$ & $61.6 \pm 2.78$ & $140.04 \pm 4.88$ & $66.29 \pm 2.09$ \\
\hline Nizhnegorskiy district & $1.37 \pm 0.06$ & $8.22 \pm 0.39$ & $45.2 \pm 2.11$ & $83.34 \pm 4.51$ & $49.31 \pm 1.94$ \\
\hline Pervomaiskiy district & $1.88 \pm 0.05$ & $9.43 \pm 0.39$ & $44.5 \pm 2.76$ & $130.63 \pm 6.02$ & $49.28 \pm 2.11$ \\
\hline Razdol'nenskiy ditsrict & $1.32 \pm 0.04$ & $8.22 \pm 0.32$ & $62.8 \pm 3.07$ & $114.70 \pm 4.31$ & $67.02 \pm 1.52$ \\
\hline Sakskiy district & $1.54 \pm 0.06$ & $11.05 \pm 0.27$ & $59.7 \pm 2.95$ & $162.47 \pm 6.53$ & $65.22 \pm 2.92$ \\
\hline Simferoplskiy district & $1.27 \pm 0.03$ & $8.65 \pm 0.41$ & $53.1 \pm 1.85$ & $91.56 \pm 3.70$ & $57.50 \pm 1.87$ \\
\hline Sovetskiy district & $1.35 \pm 0.05$ & $6.52 \pm 0.32$ & $56.5 \pm 2.78$ & $80.40 \pm 2.98$ & $59.72 \pm 2.14$ \\
\hline Chernomorskiy district & $1.98 \pm 0.07$ & $10.38 \pm 0.41$ & $48.1 \pm 1.95$ & $159.41 \pm 4.74$ & $53.29 \pm 1.84$ \\
\hline
\end{tabular}

$\mathrm{N}$ o t e : ${ }^{1}$ means energy flux density; ${ }^{2}$ means individual electromagnetic burden.

Yalta $\left.\left(156.44 \pm 6.17\left(\mu \mathrm{W} / \mathrm{cm}^{2}\right) \cdot \min \right)\right)$ and districts (Chernomorskiy (159.41 \pm 4.74 $\left.\left(\mu \mathrm{W} / \mathrm{cm}^{2}\right) \cdot \mathrm{min}\right)$ and Sakskiy $(162.47 \pm 6.53$ $\left.\left.\left(\mu \mathrm{W} / \mathrm{cm}^{2}\right) \cdot \min \right)\right)$ where individual electromagnetic burden was higher than on average in Crimea. IEB was next to minimal in some cities (Armyansk $\left(64.11 \pm 2.84\left(\mu \mathrm{W} / \mathrm{cm}^{2}\right) \cdot \min \right)$, Kerch $\left.\left(79.60 \pm 3.94\left(\mu \mathrm{W} / \mathrm{cm}^{2}\right) \cdot \mathrm{min}\right)\right)$ and districts (Belogorskiy $\left(54.13 \pm 1.87\left(\mu \mathrm{W} / \mathrm{cm}^{2}\right) \cdot \min \right)$, Dzhankoyskiy $\left(80.35 \pm 2.90\left(\mu \mathrm{W} / \mathrm{cm}^{2}\right) \cdot \min \right)$. Calculated average daily electromagnetic exposure (ADEE) varied from $49.17 \pm 1.91 \mathrm{~min}$ (Armyansk) to $72.96 \pm 1.34 \mathrm{~min}$ (Simferopol) and amounted to $60.56 \pm 1.15 \mathrm{~min}$ on average in Crimea.

Next, we applied Kendall correlation procedure to statistically calculate correlations between EFD, IEB, ADEE, and basic parameters of morbidity with diseases of the circulatory system in Crimea. We managed to detect authentic correlations between average annual
EFD and total morbidity with diseases of the circulatory system $($ Tau $=0.399 ; p<0.01)$ and primary morbidity with hypertensive diseases $($ Tau $=0.304 ; p=0.04)$; we also detected authentic correlations between IEB and total morbidity with diseases of the circulatory system $(T a u=0.437 ; p<0.01)$, total morbidity with hypertensive diseases (Tau $=0.377$; $p=0.01$ ), and primary morbidity with hypertensive diseases ( $T a u=0.342 ; p=0.02)$. Having analyzed overall annual data, we detected authentic correlations between ADEE and primary morbidity with hypertensive diseases $($ Tau $=0.299 ; p=0.04)$ and primary morbidity with cerebrovascular diseases $(\mathrm{Tau}=0.411$; $p<0.01)$.

At present there are different opinions on impacts exerted by exposure to EMR created by mobile phones on the cardiovascular system. Thus, for example, authors of a review [10] based on results obtained in several ex- 
perimental studies came to a conclusion that mobile phones didn't produce any effects on hemodynamic parameters (heart rate or blood pressure) or on electrical activity of the heart. However, authors of a similar review [11], though having mentioned absence of any effects on the heart by EMR created by mobile phone frequencies, still stressed there were certain compensatory mechanisms that would weaken over time together with growing adverse potential of probable cardiovascular effects. If we keep in mind that a disease of the circulatory system occurs after a necessary time period, such potential growth of cardiovascular effects makes our detected correlation between total morbidity with diseases of the circulatory system and EFD and IEB look quite regular. In its turn, results obtained by colleagues from India who revealed changes in blood pressure, heart rhythm, and heart rate under exposure to GSM standard electromagnetic radiation provide another illustration for our detected correlation between total morbidity with hypertensive diseases and individual energy burden $[12,13]$.

Duration of phones calls using a mobile device also has its impacts on the cardiovascular system. Szyjkowska A. and colleagues (2019) proved in their experimental study that if a person communicated over mobile phone for more than 60 minutes a day, it had significant influence on his or her blood pressure; it was authentically $(p=0.04)$ different from blood pressure of people who spent less than 1 hour a say on communicating over a mobile phone [14]. Our detected correlations between primary morbidity with hypertensive diseases and ADEE confirm these data.

Another interesting finding is a correlation between primary morbidity with cerebrovascular diseases and ADEE; it is in line with literature data on detected ischemia of the brain vessels under exposure to electromagnetic radiation created by mobile phones [15]. It is also indirectly illustrated with research works that focused on influence exerted by different EMF frequencies on hormones and enzymatic activ- ity of the brain [16]; the authors examined mechanisms that underlay effects produced by EMF at tissue and cellular levels and described how calcium channels in membranes activated as a response to exposure to EMF. Besides, in our research, we detected a difference between a place that belonged to cerebrovascular diseases in total and primary morbidity with diseases of the circulatory system as well as considerable growth in a share belonging to such diseases in primary morbidity with diseases of the circulatory system. So, we can assume that the overall structure of morbidity with diseases of the circulatory system might change in future. Given that, it seems vital to accomplish further experimental epidemiologic research focusing on adverse effects produced by exposure to EMF created by mobile phones.

Conclusion. We examined electromagnetic environment created by mobile phones in Crimea from March 2019 to February 2020; as a result, the following average parameters were determined: energy flux density (EFD), $1.43 \pm 0.04 \mu \mathrm{W} / \mathrm{cm}^{2}$; individual energy burden (IEB), $117.80 \pm 6.55\left(\mu \mathrm{W} / \mathrm{cm}^{2}\right) \cdot \mathrm{min}$; average daily electromagnetic exposure (ADEE), $60.56 \pm 1.15$ min. Having analyzed correlations between prevalence of circulatory diseases and parameters of electromagnetic environment, we revealed the following authentic correlations: between total morbidity with diseases of the circulatory system and the energy parameter of electromagnetic radiation or EFD $(T a u=0.399 ; p<0.01)$ and its integral parameter or IEB $($ Tau $=0.437 ; p<0.01)$; between total morbidity with hypertensive diseases and the integral parameter or IEB ( Tau $=0.377$, $p=0.01$ ); between primary morbidity with hypertensive diseases and all three parameters, or EFD $($ Tau $=0.304, p=0.04)$, IEB $($ Tau $=0.342$, $p=0.02)$, and ADEE $($ Tau $=0.299, p=0.04)$; between primary morbidity with cerebrovascular diseases and the time parameter of the examined factor or ADEE (Tau $=0.411, p<0.01)$. Therefore, energy and time parameters of electromagnetic environment created by mobile phones that have been measured in Crimea are 
authentically correlated with distribution of morbidity with circulatory diseases, in particular, hypertensive diseases and cerebrovascular diseases, and have their influence on growth in morbidity with diseases of the circulatory system among people living in the republic.

A research work of such type doesn't require any ethical approval.
Funding. The research was accomplished due to support provided by the Russian Foundation for Basic Research within the project No. 18-013-01028A "Influence by electromagnetic environment and exposure to mobile communication systems on dynamics of circulatory diseases spread among population".

Conflict of interests. The authors declare there is no any conflict of interests.

\section{References}

1. Yu J., Song F., Li Y., Zheng Z., Jia H., Sun Y., Jin L., Yu X. Multimorbidity analysis of 13 systemic diseases in northeast China. International Journal of Environmental Research and Public Health, 2020, vol. 17, no. 6, pp. 1817. DOI: 10.3390/ijerph17061817

2. Timmers P.R.H.J., Kerssens J.J., Minton J., Grant I., Wilson J.F., Campbell H., Fischbacher C.M., Joshi P.K. Trends in disease incidence and survival and their effect on mortality in Scotland: nationwide cohort study of linked hospital admission and death records 2001-2016. BMJ Open, 2020, vol. 10, no. 3, pp. e034299. DOI: 10.1136/bmjopen-2019-034299

3. Tolochko V. Analysis of the sickness rate and the mortality from the diseases of the blood circulatory system in Gomel region. Sakharovskie chteniya 2018 goda: Ekologicheskie problemy XXI veka: materialy 18-i mezhdunarodnoi nauchnoi konferentsii. In: S.A. Maskevich, S.S. Poznyak eds., vol. 1, no. 1 , pp. 352.

4. Arnett D.K., Blumenthal R.S., Albert M.A., Buroker A.B., Goldberger Z.D., Hahn E.J., Himmelfarb C.D., Khera A. [et al.]. 2019 ACC/AHA Guideline on the Primary Prevention of Cardiovascular Disease: A Report of the American College of Cardiology/American Heart Association Task Force on Clinical Practice Guidelines. J. Am. Coll. Cardiol., 2019, vol. 74, no. 10, pp. 1376-1414.

5. Kiku P.F., Beniova S.N., Moreva V.G., Gorborukova T.V., Izmaylova O.A., Sukhova A.V., Sabirova K.M., Bogdanova V.D. Ecological and hygienic factors and prevalence of the diseases of the circulatory system. Zdravookhranenie Rossiiskoi Federatsii, 2019, vol. 63, no. 2, pp. 92-97. DOI: 10.18821/0044-197X-2019-63-2-92-97 (in Russian).

6. Baliatsas C., Bolte J., Yzermans J., Kelfkens G., Hooiveld M., Lebret E., van Kamp I. Actual and perceived exposure to electromagnetic fields and non-specific physical symptoms: an epidemiological study based on self-reported data and electronic medical records. Int. J. Hyg. Environ. Health, 2015, vol. 218, no. 3, pp. 331-344. DOI: 10.1016/j.ijheh.2015.02.001

7. Malek F., Rani K.A., Rahim H.A., Omar M.H. Effect of Short-Term Mobile Phone Base Station Exposure on Cognitive Performance, Body Temperature, Heart Rate and Blood Pressure of Malaysians. Sci. Rep., 2015, vol. 5, pp. 13206. DOI: 10.1038/srep13206

8. Yashchenko S.G., Rybalko S.Yu. The prevalence of cardiovascular disease due to electromagnetic loads generated by mobile communication. Gigiena i sanitariya, 2019, vol. 98, no. 11, pp. 1302-1308. DOI: 10.18821/0016-9900-2019-98-11-1302-1308 (in Russian).

9. Beekhuizen J., Heuvelink G.B., Huss A., Bürgi A., Kromhout H., Vermeulen R. Impact of input data uncertainty on environmental exposure assessment models: A case study for electromagnetic field modeling from mobile phone base stations. Environ. Res., 2014, vol. 135, pp. 148-155. DOI: 10.1016/j.envres.2014.05.038

10. Kirti, Duhan M. A Study of Affected Cardiac Activities Due to the Use of Mobile Phones. International Journal of Trend in Research and Development, 2016, vol. 3, no. 4, pp. 36-38.

11. Elmas O. Effects of electromagnetic field exposure on the heart: a systematic review. Toxicology and Industrial Health, 2016, vol. 32, no. 1, pp. 76-82. DOI: 10.1177/0748233713498444

12. Mitra R., Mazumder M., Pal K., Jana S. A study on effect of mobile phone radiation on human health. Explor. Anim. Med. Res., 2014, vol. 4, no. 2, pp. 246-252.

13. Paul B., Saha I., Kumar S., Ferdows S.K.S., Ghose G. Mobile phones: Time to rethink and limit usage. Indian. J. Public. Health, 2015, vol. 59, no. 1, pp. 37-41. DOI: 10.4103/0019-557X.152856 
14. Szyjkowska A., Gadzicka E., Szymczak W., Bortkiewicz A. [The reaction of the circulatory system to stress and electromagnetic fields emitted by mobile phones - 24-h monitoring of ECG and blood pressure]. Med. Pr., 2019, vol. 70, no. 4, pp. 411-424. DOI: 10.13075/mp.5893.00805 (in Polish).

15. Malikova M.A., Kaliaev A.O., Sukhoruchkin A.A., Bakhmetev A.S. The effect of mobile phone electromagnetic radiation on brain vessels. Surg. Case Rep. Rev., 2017, vol. 1, no. 1, pp. 1-3. DOI: $10.15761 /$ SCRR.1000104

16. Warille A.A., Altun G., Elamin A.A., Kaplan A.A., Mohamed H., Yurt K.K., Elhaj A.E. Skeptical approaches concerning the effect of exposure to electromagnetic fields on brain hormones and enzyme activities. J. of Microsc. Ultrastruct., 2017, vol. 5, no. 4, pp. 177-184. DOI: 10.1016/j.jmau.2017.09.002

Shibanov S.E., Yashchenko S.G., Rybalko S.Yu. Electromagnetic environment created by mobile communication as a risk factor causing higher prevalence of circulatory diseases. Health Risk Analysis, 2021, no. 3, pp. 77-83. DOI: 10.21668/health.risk/2021.3.07.eng

Received: 16.08 .2021

Accepted: 20.09.2021

Published: 30.09 .2021 